\title{
SYSTEM ATIC OFF-PUMP CORONARY ARTERY REVASCULARIZATION IN MULTIVESSEL DISEASE: EXPERIENCE OF THREE HUNDRED CASES
}

Raymond Cartier, MD

Stacey Brann, $\mathrm{MD}^{\mathrm{b}}$

François Dagenais, $\mathrm{MD}^{\mathrm{b}}$

Raymond Martineau, $\mathrm{MD}^{\mathrm{c}}$

André Couturier, $\mathrm{MSc}^{\mathrm{d}}$
Objective: We sought to report our recent experience with off-pump coronary artery revascularization in multivessel disease. Methods: Between October 1996 and December 1998, 300 off-pump beating heart operations were performed at the Montreal Heart Institute by a single surgeon, representing $94 \%$ of all procedures undertaken during this same time frame (97\% for 1998). This cohort of patients was compared with 1870 patients operated on with cardiopulmonary bypass from 1995 to 1996. Results: Mean age, sex distribution, and preoperative risk factors were comparable for the two groups. On average, $2.92 \pm 0.8$ and $2.84 \pm$ 0.6 grafts per patient were completed in the beating heart and cardiopulmonary bypass groups, respectively. A majority of patients (70\%) had either a triple or quadruple bypass. Coronary anastomoses were achieved with myocardial mechanical stabilization and heart "verticalization." Ischemic time was shorter in the beating heart group $(29.8 \pm$ 0.9 vs $45 \pm 0.4$ minutes, $P<.05)$. Similarly, the need for transfusion was significantly less in the beating heart group (beating heart operations, $34 \%$; cardiopulmonary bypass, $66 \% ; P<.005)$. Reduced use of postoperative intra-aortic counterpulsation, as well as a lower rise in creatine kinase MB isoenzyme, was observed in the beating heart group. Operative mortality rates (beating heart operations, 1.3\% ; cardiopulmonary bypass, $2 \%$ ) and perioperative myocardial infarction (beating heart operations, $3.6 \%$; cardiopulmonary bypass, $4.2 \%$ ) were comparable for the two groups. Conclusion: In a majority of patients, off-pump complete coronary artery revascularization is an acceptable alternative to conventional operations, yielding good results given progressive experience, rigorous technique, and adequate coronary artery stabilization. (J Thorac Cardiovasc Surg 2000;119:221-9)
$\mathrm{D}$ uring the past few years, an increasing number of surgeons have rehabilitated the practice of unsupported beating heart coronary operations for select groups of patients. Popularized by Kolesov ${ }^{1}$ in the early 1960s, the technique has recently regained surgeons'

From the Departments of Cardiac Surgery, ${ }^{\mathrm{a}}$ Anesthesiology, ${ }^{\mathrm{c}}$ and Biostatistics, ${ }^{\mathrm{d}}$ Montreal Heart Institute, and the Department of Cardiac Surgery, ${ }^{b}$ University of Montreal, Montreal, Quebec, Canada.

Read at the Seventy-ninth Annual Meeting of The American Association for Thoracic Surgery, New Orleans, La, April 18-21, 1999.

Received for publication April 22, 1999; revisions requested June 29, 1999; revisions received Nov 1, 1999; accepted for publication Nov 2, 1999.

Address for reprints: Raymond Cartier, MD, Montreal Heart Institute, Research Center, 5000 Belanger St E, Montreal, Quebec, Canada H1T 1C8 (E-mail: cartierr@icm.umontreal.ca).

Copyright $\odot 2000$ by Mosby, Inc.

$0022-5223 / 2000 \$ 12.00+0 \quad \mathbf{1 2 / 6 / 1 0 4 1 6 0}$ attention as a minimally invasive and alternative approach to conventional operation. By avoiding sternotomy in favor of a small anterior thoracotomy, minimally invasive direct coronary artery bypass grafting (MIDCAB) rapidly attracted interest as a new technique, albeit limited mostly to patients with single-vessel disease. ${ }^{2}$ Consequently, the surgeons' focus in minimally invasive technique rapidly shifted toward the avoidance of cardiopulmonary bypass (CPB) rather than the sternotomy itself to potentially treat the significantly larger number of patients affected with multivessel disease. Long considered the gold standard, CPB-supported coronary operations are recently being questioned because the procedure is still characterized by a significant number of side effects. . $^{3,4}$

Initially, the beating heart operative technique was deemed to be more technically demanding; however, the recent introduction and continuous improvement in 


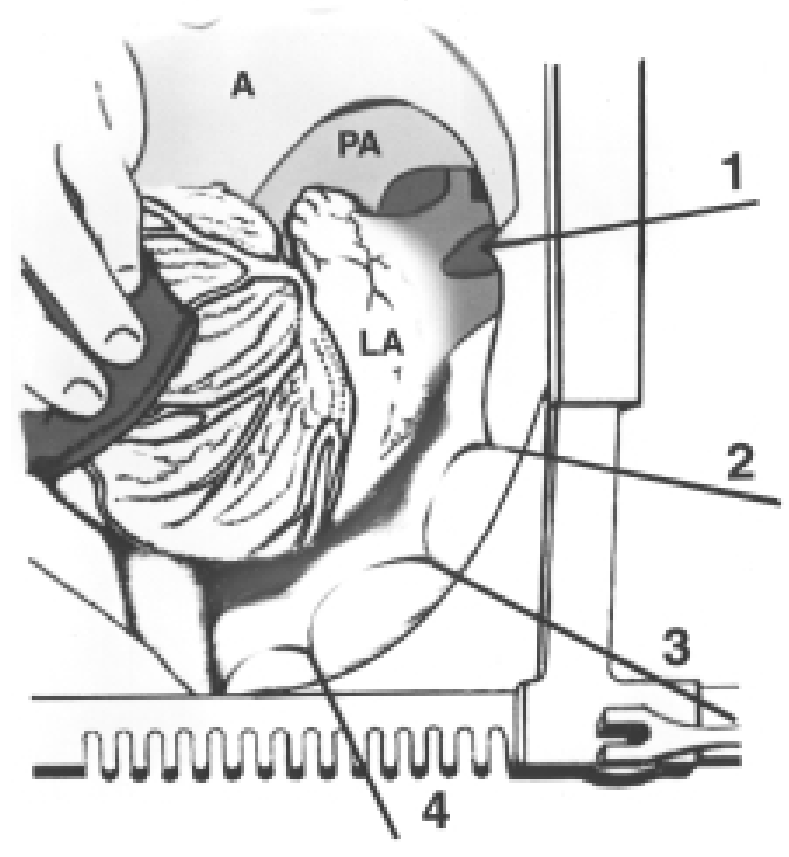

Fig 1. The site of the pericardial stitches used to verticalize the heart. The first stitch (1) is located between the superior and the inferior left pulmonary veins close to the pericardial reflection $(<1 \mathrm{~cm}$ from the vein bifurcation). The second stitch (2) is placed below the left inferior pulmonary vein. Once the first 2 stitches are anchored, a pericardial "ridge" is formed, which serves as a guide for implantation of the other stitches. The third stitch (3) is located between the second and the inferior vena cava, and the last stitch (4) is located close to the inferior vena cava. $A$, Aorta; $P A$, pulmonary artery; $L A$, left atrium.

coronary mechanical stabilizers has considerably improved the feasibility and outcome of these procedures. Although the beating heart operative technique was shown to be a suitable alternative to conventional CPB operations in select patients carrying high surgical risk, it has not been considered on a systematic basis for a majority of patients. ${ }^{5}$

To qualify as an alternative approach to conventional operations, beating heart operations must respond to all anatomies, use similar vascular conduits, achieve equivalent technical results and comparable mortality and morbidity rates, and maintain a low conversion rate to on-pump operations. Furthermore, the ability to provide the patient with as complete a coronary revascularization as possible should not be compromised through the beating heart operation approach because this represents a major benefit for the patient. 6,7 Since October 1996, we have developed and adopted the practice of systematic off-pump coronary artery revas- cularization at the Montreal Heart Institute. This report describes our experience with this technique while comparing it with conventional CPB operations.

\section{Patients and methods}

Between October 1996 and December 1998, we completed 300 coronary artery revascularizations without $\mathrm{CPB}$, the majority (>270 cases) of which were systematically approached, meaning that all patients were considered for the beating heart operation technique. This represents $94 \%$ of the coronary revascularization caseload during this same period, and 97\% of all procedures were performed during 1998. These patients were prospectively followed up and compared with a control cohort of 1870 patients operated on with CPB during 1995 and 1996 by all cardiac surgeons working at the Montreal Heart Institute during this period. All off-pump operations were done by a single surgeon (R.C.). The CPB cohort was selected from this earlier period to segregate post1996 off-pump beating heart operations and be demographically representative of a standard cohort of surgical patients. After 1996, a significant number of coronary revascularizations were completed off-pump at our institution. All salvage procedures were excluded in both groups. Salvage procedures were defined as patients rushed into the operating room with unstable hemodynamics or severe ischemia that could not be stabilized preoperatively. These patients, because of their unstable preoperative hemodynamics, had to be operated on in conjunction with CPB. Fifty-six $(2.9 \%)$ of these patients were excluded from the CPB group.

Surgical contraindications for beating heart operations. After the first 30 off-pump bypass procedures, all patients were considered as potential candidates. Only patients $(<1 \%)$ with deep intramyocardial left anterior descending (LAD) arteries or with very unstable preoperative hemodynamics were not considered for the procedure. Reoperative procedures, during which patent but atheromatous grafts fed occluded native coronary arteries, were considered relative contraindications if partial aortic clamping of the ascending aorta was anticipated, thereby causing a potential ischemic threat.

Off-pump surgical technique. The technique we used has already been described. ${ }^{8,9}$ In brief, most of the procedures (>99\%) were approached through a standard sternotomy under general anesthesia (narcotics, benzodiazepines, and pancuronium). Occasional boluses of metoprolol were administered to maintain heart beat below 80 beats/min when indicated. Pressure drop and electrocardiographic ST-segment modifications were treated with infusion of phenylephrine and nitroglycerin, respectively, as indicated.

The distal right artery and the LAD artery were directly accessed with very little heart manipulation. The posterior descending artery (PDA) and the obtuse marginal artery were accessed by more extensive mobilization of the posterior pericardium. For the circumflex territory, this consisted in positioning 4 traction sutures spaced between the left superior pulmonary vein and the inferior vena cava (Fig 1). The 

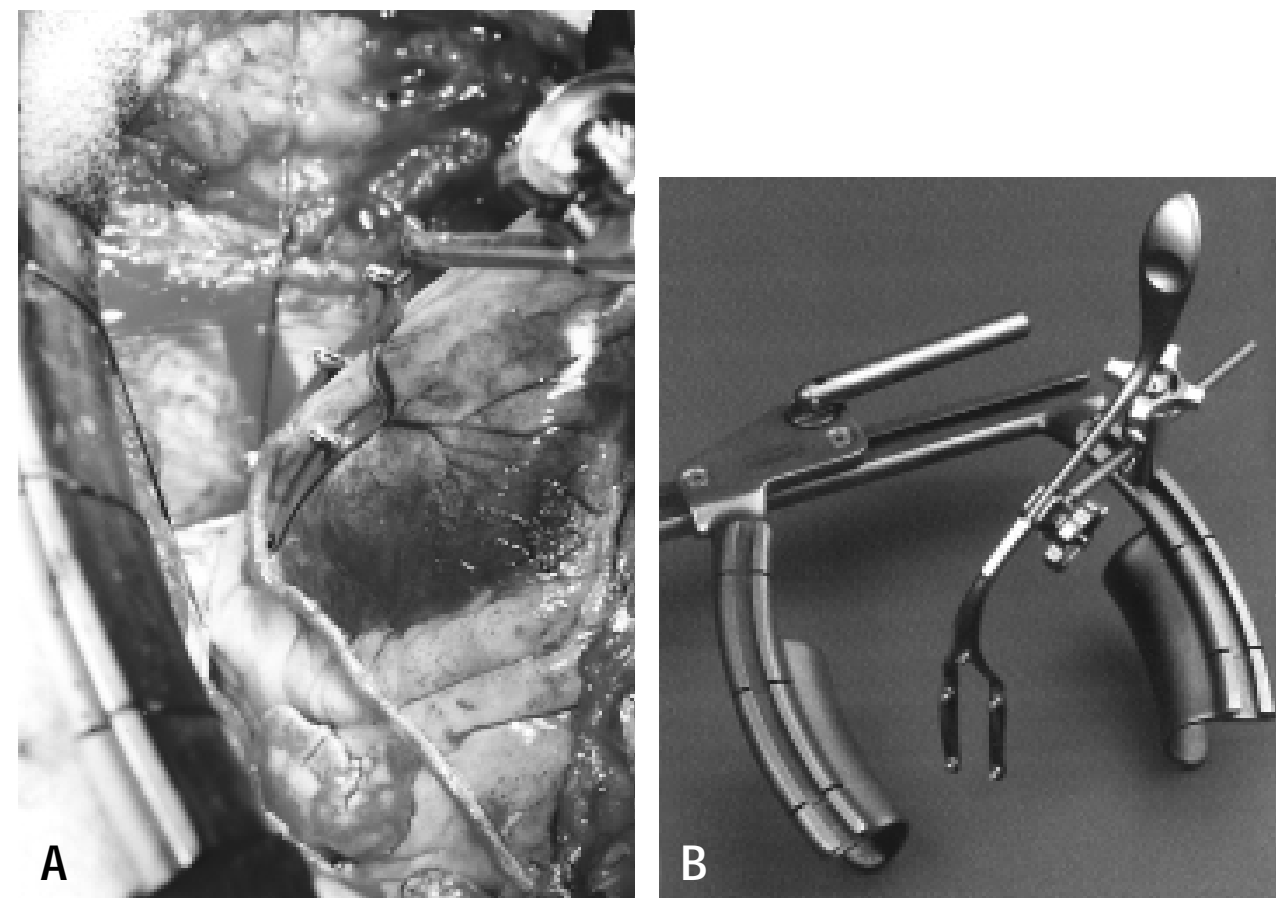

Fig 2. A, The posterior wall stabilizer positioned for completion of a second obtuse marginal graft. B, CoroNéo Cor-Vasc device used for posterior wall stabilization.

sutures were placed far below the phrenic nerve at the level of the pericardial reflection. No pericardial counterincision to create heart herniation through the right chest was used and in none of the cases was the need for a right ventricular assist device necessitated. Vessel occlusion was achieved through external encircling with silicone rubber bands (Retract-otape; Quest Medical Inc, Allen, Tex). No intraluminal occlusive device, shunt, or gas insufflation was used. Coronary artery immobilization was achieved with specially designed reusable mechanical stabilizers (Cor-Vasc System [patent pending]; CoroNéo Inc, Montreal, Canada; Fig 2, $A$ and $B$ ).

The following revascularization strategy was adopted: the most collateralized vessel was always bypassed first to provide a backup to the less severely stenotic vessels; all proximal anastomoses were completed during a single partial clamping of the aorta; and the PDA was generally favored over the distal right coronary artery to avoid atrioventricular block.

On-pump surgical technique. Coronary revascularization with $\mathrm{CPB}$ was performed under moderate hypothermia $\left(32^{\circ} \mathrm{C}-34^{\circ} \mathrm{C}\right)$ with a membrane oxygenator (Monolyth; Sorin Biomedica, Inc, Richmond Hill, Canada) equipped with an arterial air filter (Terumo; CardioMed Supplies, Inc, Gormley, Canada). Cardioplegic arrest was achieved with a hyperkalemic cold cardioplegic blood solution. In the majority of patients, the CPB circuit was primed with crystalloid solution.

Follow-up. Short-term (3 months) follow-up was completed on $99 \%$ of the beating heart operation group. However, midterm (>6 months) follow-up was completed only in $30 \%$ of the patients.

Statistics. Data are expressed as mean values \pm SD. Comparisons between the two groups are established with unpaired $t$ tests (2-tailed) for continuous variables and with the $\chi^{2}$ and Fisher exact tests for discrete variables. For data presenting skewed distribution, results are expressed as the median and 25th and 75th percentiles along with minimum and maximum, and the Kruskal-Wallis test is used for statistical comparisons. For continuous variables studied in different time frames, a 2-way analysis of variance for repeated measures on factor time was used.

\section{Results}

Demographics and risk factors. The two groups were comparable in terms of age, sex distribution, and standard risk factors, except for the prevalence of unstable angina, which was higher in the CPB group (Table I). Similarly, the preoperative left ventricular ejection fraction (LVEF), the prevalence of left ventricular dysfunction as defined by an LVEF of less than $40 \%$, previous coronary operations, significant left main disease, and the use of a preoperative intra-aortic counterpulsation device were the same for both populations.

Perioperative technical data. The average number of grafts per patient, as well as the graft distribution, 
Table I. Demographics and perioperative risk factors

\begin{tabular}{lccc}
\hline & $\begin{array}{c}\text { Beating heart } \\
\text { operation } \\
(n=300)\end{array}$ & $\begin{array}{c}\text { CPB } \\
(n=1870)\end{array}$ & P value \\
\hline Age (y) & $63 \pm 10$ & $62.5 \pm 10$ & .4 \\
Sex ratio (M/F) & 3.47 & 3.34 & .4 \\
Diabetes & $24 \%$ & $24 \%$ & .95 \\
HBP & $48 \%$ & $46 \%$ & .12 \\
Tobacco & $33 \%$ & $29 \%$ & .18 \\
COPD & $9 \%$ & $8 \%$ & .6 \\
LVEF & $54 \% \pm 10 \%$ & $54 \% \pm 13 \%$ & 1.00 \\
LVEF < 40\% & $15 \%$ & $16 \%$ & .7 \\
Previous operation & $7 \%$ & $8 \%$ & .2 \\
Unstable angina & $60 \%$ & $69 \%$ & .002 \\
LMS > 50\% & $26 \%$ & $22 \%$ & .14 \\
Preoperative IABP & $5 \%$ & $5 \%$ & .9 \\
\hline
\end{tabular}

$H B P$, High blood pressure; $C O P D$, chronic obstructive pulmonary disease; $L M S$, left main stenosis; $I A B P$, intra-aortic balloon pump.

Table II. Technical data

\begin{tabular}{lccc}
\hline & $\begin{array}{c}\text { Beating heart } \\
\text { operation } \\
(n=300)\end{array}$ & $\begin{array}{c}\text { CPB } \\
(n=1870)\end{array}$ & P value \\
\hline Grafts per patient & $2.93 \pm 0.87$ & $2.84 \pm 0.74$ & .06 \\
Ischemic time (min) & $28 \pm 11$ & $45 \pm 17$ & .001 \\
Graft distribution & & & \\
Single & $5 \%$ & $2.3 \%$ & .02 \\
Double & $23.3 \%$ & $29 \%$ & .04 \\
Triple & $47 \%$ & $52 \%$ & .12 \\
Quadruple & $22 \%$ & $16 \%$ & .01 \\
Quintuple & $2.7 \%$ & $0.7 \%$ & .003 \\
Coronary territory grafted & & & \\
$\quad$ LAD & $95 \%$ & $95 \%$ & .9 \\
$\quad$ Diagonal & $30 \%$ & NA & \\
Circumflex & $73 \%$ & $63 \%$ & .001 \\
$\quad$ Right & $78 \%$ & $73 \%$ & .08 \\
Complete & $93 \%$ & NA & \\
$\quad$ revascularization & & & \\
Conversion rate to CPB & $0.4 \%$ & &
\end{tabular}

$N A$, Not available.

are displayed in Table II. A trend toward a higher number of grafts was observed in the beating heart operation group $(P=.057)$, and this is reflected in the graft distribution. The rate of complete revascularization achieved in the beating heart operation group was $93 \%$. Revascularization was considered incomplete when a territory was judged surgically nonreconstructable or when a suitable vessel was discarded for technical reasons. Only one conversion to CPB was necessitated in the beating heart operation group, and this was subsequent to a side-clamping related aortic dissection. The patient underwent an ascending aortic replacement
Table III. Ischemic interval relative to revascularized territory

\begin{tabular}{lcc}
\hline Artery & $\begin{array}{c}\text { Median }^{*} \\
\text { (minimum-maximum) }\end{array}$ & $\begin{array}{c}\text { 25th-75th } \\
\text { percentile }\end{array}$ \\
\hline LAD & $9(4-43)$ & $8-12$ \\
Diagonal & $8(4-32)$ & $6-9$ \\
Obtuse marginal & $8(4-45)$ & $7-10$ \\
Posterior descending & $8(4-23)$ & $6-10$ \\
Right coronary & $8(5-19)$ & $7-11$ \\
Posterolateral & $7.5(5-16)$ & $7-10$ \\
\hline
\end{tabular}

*In minutes.

Table IV. Vascular conduits

\begin{tabular}{|c|c|c|c|}
\hline Conduits & $\begin{array}{l}\text { Beating heart } \\
\text { operation } \\
\quad(n=300)\end{array}$ & $\begin{array}{c}C P B \\
(n=1870)\end{array}$ & $\mathrm{P}$ value \\
\hline Internal thoracic artery & $96 \%$ & $93 \%$ & .07 \\
\hline Radial artery & $12 \%$ & $0 \% *$ & \\
\hline Saphenous vein & $84 \%$ & $94 \%$ & .001 \\
\hline
\end{tabular}

"No radial artery grafts were used in our institution before 1997.

with a Dacron graft and had an uneventful recovery. The average ischemic interval relative to the revascularized territory is presented in Table III. On average, the use of arterial and vein conduits was comparable in both groups (Table IV). The use of the radial artery as a conduit was only introduced in our institute after 1996. Coronary endarterectomies, with or without vein patch angioplasty, were completed in $9 \%$ of the beating heart operation group.

Postoperative bleeding and transfusion needs. Perioperative blood loss was significantly lower in the beating heart operation group. A tremendous difference was observed in the transfusion needs between both groups (Table V). The beating heart operation group was transfused half as often as the CPB group. Furthermore, among the patients who received a transfusion, red cell pack requirements were similar for the two groups, whereas the amount of blood products administered, including fresh frozen plasma, platelet packs, or cryoprecipitates, were significantly less in the beating heart operation group.

Hematology and biochemistry. These two profiles are presented in Table VI. The postoperative and discharge hemoglobin count was significantly higher in the beating heart operation group. The postoperative creatinine serum level rose more significantly in the CPB group. The average postoperative cardiac subunit creatine kinase MB (CK-MB) was also significantly lower in the beating heart operation group the day of 
Table V. Postoperative bleeding and transfusion need

\begin{tabular}{lccc}
\hline & Beating heart operation $(n=300)$ & CPB $(n=1870)$ & P value \\
\hline $\begin{array}{l}\text { Blood loss } \\
\text { Operative }\end{array}$ & $400(50-1500) ; 250-500$ & $400(100-3500) ; 350-600$ & .0001 \\
Postoperative & $525(0-3500) ; 325-775$ & $575(0-6850) ; 300-975$ & .008 \\
Blood transfusion & & & $<.0001$ \\
Prevalence & $31 \%$ & $65 \%$ & .08 \\
RCP per patient ${ }^{\dagger}$ & $2.7 \pm 2.2$ & $3.0 \pm 2.8$ & $<.005$ \\
TBP per patient & $4.9 \pm 7.4$ & $6.7 \pm 10.0$ & .00 \\
\hline
\end{tabular}

$R C P$, Red cell packs; $T B P$, total blood products.

${ }^{*}$ Results are expressed as median (minimum-maximum); 25 th-75th percentile.

${ }^{\dagger}$ Red cell packs per transfused patient.

¥Total blood products per transfused patient.

Table VI. Hematology and biochemistry

\begin{tabular}{|c|c|c|c|}
\hline & Beating heart operation $(n=300)$ & $C B P(n=1870)$ & $\mathrm{P}$ value \\
\hline \multicolumn{4}{|l|}{$\mathrm{HB}(\mathrm{g} / \mathrm{L})$} \\
\hline Preoperative & $134 \pm 16$ & $137 \pm 16$ & .003 \\
\hline Postoperative & $88 \pm 14$ & $80 \pm 11$ & .0001 \\
\hline Discharge & $107 \pm 13.5^{*}$ & $102 \pm 15^{*}$ & .0001 \\
\hline \multicolumn{4}{|c|}{ Creatinine $(\mathrm{mmol} / \mathrm{L})$} \\
\hline Preoperative & $103 \pm 30$ & $107 \pm 47$ & .15 \\
\hline Postoperative & $105 \pm 40$ & $125 \pm 69^{*}$ & $<.0001$ \\
\hline \multicolumn{4}{|l|}{ CK-MB (IU/L) $)^{\dagger}$} \\
\hline Day 0 & $8(1-85) ; 6-10$ & $28(0-619) ; 22-37$ & $<.0001$ \\
\hline Day 1 & $9(0-258) ; 6-16$ & $16(0-429) ; 11-26$ & $<.0001$ \\
\hline Day 2 & $9(1-140) ; 6-14^{*}$ & $10(0-435) ; 7-15^{\ddagger}$ & .3 \\
\hline
\end{tabular}

$H B$, Hemoglobin; $C K-M B$, creatine kinase MB.

${ }^{*}$ Variation within group: $P=.0001$ for each period.

${ }^{\dagger}$ Results are expressed as median (minimum-maximum); 25th-75th percentile.

ॠVariation within group: $P<.01$ for each period.

the operation and the following day. By the second postoperative day, there no longer was a significant difference.

Postoperative morbidity rates. The list of the most common perioperative complications for both groups is presented in Table VII. The incidence of myocardial infarction (MI; Q and non-Q wave) was equivalent in the two cohorts. MI was defined as either a maximal CK-MB level of greater than $100 \mathrm{IU} / \mathrm{L}$, any new abnormal wall motion detected by echocardiography not present before the operation, or a positive technetium pyrophosphate radionucleide scan. Interestingly, the incidence of atrial fibrillation and cerebrovascular accident remained similar in the two groups. The use of postoperative inotropic agents was the same in the two groups. A trend toward a shorter postoperative hospital stay was observed in the beating heart operation group.

Postoperative mortality rate. The operative mortality rate was $1.3 \%$ and $2 \%$ in the beating heart operation and CPB groups, respectively. Causes of death in the beating heart operation group (4 patients) were as fol- lows: multiorgan failure caused by a perioperative sternal hemorrhage on day 7; persistent malignant arrhythmia on day 21 (present preoperatively and noncontrollable postoperatively); aortic dissection occurring 1 week postoperatively; and sudden death on day 13 after the operation without a history of perioperative MI or low-output syndrome. No death was directly related to a cardiogenic shock caused by perioperative MI. Among the 38 deaths that occurred in the CPB group, $28(60 \%)$ were caused by postoperative hemodynamic causes, including low cardiac output; 5 (13\%) caused by multiorgan failure; 4 (10\%) caused by pulmonary insufficiency; 1 (2.6\%) caused by neurologic causes; and $5(13 \%)$ caused by miscellaneous causes.

Recurrence of angina. Five patients in the beating heart operation group experienced early ( $<2$ months) recurrence of angina. One patient had an acute occlusion of a PDA graft on the third postoperative day. He underwent a successful percutaneous transluminal coronary angioplasty of the distal right artery. Interestingly, the distal anastomosis was patent and was 
Table VII. Postoperative morbidity

\begin{tabular}{|c|c|c|c|}
\hline & $\begin{array}{c}\text { Beating heart } \\
\text { operation } \\
\quad(n=300)\end{array}$ & $\begin{array}{c}C P B \\
(n=1870)\end{array}$ & $\mathrm{P}$ value \\
\hline Reoperation $^{*}$ & $5 \%$ & $8 \%$ & .9 \\
\hline Atrial fibrillation & $30 \%$ & $31 \%$ & .8 \\
\hline Infection & $4.6 \%$ & $6 \%$ & .4 \\
\hline Pulmonary complication & $10 \%$ & NA & \\
\hline CVA and TCI & $1.6 \%$ & $1.6 \%$ & .8 \\
\hline Postoperative IABP & $0.8 \%$ & $5 \%$ & .002 \\
\hline MI & $4.0 \%$ & $4.2 \%$ & .99 \\
\hline $\begin{array}{l}\text { Postoperative inotropic } \\
\text { support }\end{array}$ & $32 \%$ & $34 \%$ & .95 \\
\hline Hospital stay (d) & $6.9 \pm 7.3$ & $7.5 \pm 5.5$ & .1 \\
\hline
\end{tabular}

not related to the technical failure of the bypass. Three other patients underwent follow-up coronary angiograms 3 to 6 months after the operation. Of these, 2 showed patency of all grafts with diffused disease. One showed occlusion of two vein grafts made on an endarterectomized PDA and a third obtuse marginal artery. These vessels were of small caliber $(1.25 \mathrm{~mm})$ and were described as diffusely atheromatous. These 3 patients were treated medically. Another patient, who did not have a follow-up angiogram but did have a nuclear stress test, had a localized ischemic area and was also treated medically.

Two patients had midterm (>2 months) recurrent angina. One was reinvestigated by angiography. A venous graft stenosis was found $(2 \mathrm{~cm}$ from the proximal aortic anastomosis), and a successful percutaneous transluminal coronary angioplasty was performed. The other patient was treated medically. Both are in New York Heart Association functional class I.

Midterm mortality rates. We report 9 midterm deaths (>1 month) in the beating heart operative technique groups, and causes of death are presented in Table VIII. There were only 2 cardiac-related deaths. An 86-year-old patient died of chronic heart failure subsequent to multiple pulmonary emboli. Unfortunately, this condition was diagnosed only after the heart operation. Another patient died 2 months postoperatively because of chronic heart failure.

\section{Discussion}

The advent of MIDCAB has sparked renewed interest among surgeons in off-pump coronary artery revascularization. Although initially seen as an ideal procedure for the patient, because both the full sternotomy
Table VIII. Midterm mortality rates

\begin{tabular}{lcc}
\hline Causes & Age $(y)$ & $\begin{array}{c}\text { Postoperative } \\
\text { period }(w k)\end{array}$ \\
\hline Propafenone intoxication & 77 & 8 \\
Neurologic & 78 & 12 \\
Right heart failure & 86 & 24 \\
Abdominal & 90 & 20 \\
Tracheo-innominate fistula & 74 & 5 \\
Septic shock & 61 & 13 \\
Cardiac insufficiency & 59 & 10 \\
Chronic renal insufficiency & 74 & 60 \\
Suicide & 63 & 8 \\
\hline
\end{tabular}

and $\mathrm{CPB}$ run were avoided, the MIDCAB procedure did not respond fully to original expectations. Anterior thoracotomies may occasionally be more painful than anticipated. The limited MIDCAB exposure to the mediastinal territory, coupled with the need for single lung deflation, makes the harvesting of the internal thoracic artery and subsequent coronary grafting substantially more time consuming and technically more demanding. Furthermore, because the usual space afforded by conventional coronary artery bypass grafting (CABG) through full sternotomy is compromised, surgical complications necessitating urgent conversion to CPB become more likely.

In terms of its applicability, the MIDCAB procedure is mostly limited to patients with single-vessel disease, which, for the average practice in our experience, represents about $5 \%$ of the cardiac operation caseload. The conventional sternotomy, in addition to providing surgeons with an accustomed approach, allows them to concentrate on the prime task (ie, CABG on the beating heart). This is probably an easier first step in evolving cardiac operations toward a less invasive procedure by the elimination of CPB. Next, steps can focus on achieving this beating heart operative procedure through smaller incisions or port incisions. A conventional sternotomy provides access to all coronary territories, thereby allowing full or complete revascularization. More important, the retracted rib cage allows the surgeon the ability to "verticalize" the beating heart to gain access to the posterior arteries. Considering that more than $70 \%$ of the surgical candidates have triplevessel disease, this beating heart approach with conventional sternotomy is clearly applicable to a larger group of patients.

Since the beginnings of CABG operations for coronary atheromatous disease, the off-pump approach has always been present. Anecdotally known in the $1950 \mathrm{~s},{ }^{10}$ the beating heart operative technique was real- 
ly launched by Kolesov ${ }^{1}$ in the 1960s. Even with the introduction of $\mathrm{CPB}$, some surgeons continued, mainly for economic reasons, to perform beating heart operations and reported extensive series with excellent results. ${ }^{11-13}$

Avoiding $\mathrm{CPB}$ is a major step in rendering $\mathrm{CABG}$ less invasive. The inflammatory reaction initiated by $\mathrm{CPB}$ has always been seen as a significant threat. ${ }^{3} \mathrm{CPB}$ initiation activates the contact system to produce kallikrein, a powerful neutrophil activator. The complement system is also activated, producing anaphylatoxin C3a, C4a, and C5a, all of which are vasoactive substances. The activated neutrophils can potentially release many cytotoxic enzymes, and the monocytes, although more slowly activated, express tissue factor that initiates the extrinsic coagulation pathway. All these substances cause edema, decrease myocardial contractility, change vascular resistance, and mediate the principal complications of $\mathrm{CPB}$, such as bleeding, thromboembolism, fluid retention, and temporary organ dysfunction. ${ }^{14}$

In the present study two comparable cohorts of patients in terms of age, sex distribution, and preoperative risk factors underwent two different $\mathrm{CABG}$ techniques. Only the prevalence of unstable angina was slightly more prominent in the CPB group. The two groups had a comparable average number of grafts performed per patient, with similar graft distribution relative to the different coronary territory being grafted. The rate of complete revascularization was greater than 90\% in the beating heart operation group, and conversion to $\mathrm{CPB}$ was inferior to $1 \%$. Average ischemic time was less in the beating heart operation group than in the CPB group. Operative blood loss was substantially lower in beating heart operations, as reflected by a transfusion need that was halved in this group. Furthermore, among the patients receiving transfusions, fewer derivative blood products were administered in the beating heart operation group. Postoperative and discharge hemoglobin count was significantly higher in the beating heart operation group, whereas the rise in postoperative creatinine level was very low compared with the CPB group. There was a significant trend toward a better myocardial preservation in the beating heart operation group as outlined by the lower rise in postoperative CK-MB and a less frequent need for intra-aortic balloon pumps for left ventricular assistance. This has already been reported by Pfister and colleagues ${ }^{13}$ in a matched case study, as well as by others. ${ }^{15,16}$ The operative mortality rate was comparable in both groups; however, a larger proportion of deaths in the CPB group was due to postopera- tive low cardiac output syndrome. The rate of perioperative MI, which includes Q-wave and non-Q-wave infarction, was similar in the two groups, suggesting that this complication is not dependent on technique.

Of notable interest among postoperative complications is the incidence of atrial fibrillation (AF), which was comparable to the incidence reported by others under similar circumstances. ${ }^{17}$ In contrast, Galloway and coworkers, ${ }^{18}$ who recently published the first report of the Port-Access International Registry, reported a $5 \%$ rate of new onset of postoperative AF with Port-Access CABG (with CPB). Being proposed as a possible explanation for this decreased incidence is the absence of right atriotomy incision and suture line, as well as fewer atrial manipulations with the Port-Access technique. Because right atrial manipulations are minimal during beating heart operations, it is our opinion that some other explanation may have to be given. The length of the pericardiotomy might be a factor because it is minimized during Port-Access operations.

There was no difference in the incidence of inotropic support after the operation, infection, reintervention for either postoperative bleeding or sternal dehiscence, and cerebrovascular accident (CVA) in both groups. However, the two CVAs that occurred in the beating heart operation group were noted 4 and 5 days postoperatively subsequent to an AF episode. No case of deep mediastinitis occurred in the beating heart operation group, and no patient had acute respiratory distress syndrome. Pulmonary complications reported (10\%) include prolonged intubation ( $>24$ hours), persistent atelectasis, and pneumothorax. This latter complication seemed more frequent than expected and may be related to the placement of the deep pericardial sutures. During this maneuver, it is imperative to deflate the lung to decrease the risk of damage from the pericardial suture needle. The surgeon must be aware of this possible complication and leave the pericardium penetration as superficial as possible.

The low-CPB conversion rate reported in this series is due to the strict adherence to the revascularization strategy adopted from the onset of this series. It consists of beginning with the most collateralized vessel and providing forward flow in the graft as soon as possible to serve as a vascular backup for the next generally less-collateralized target vessel. All proximal anastomoses were completed in the same partial side-clamping. Furthermore, avoiding the crossclamping of the distal right coronary artery in case of noncritical stenosis decreased the incidence of intraoperative ventricular block. Occasional crossclamping of the inferior vena cava by external snaring was found to be 
complimentary in the control of temporary rise of pulmonary pressure with left ventricular overload. This maneuver afforded time for the anesthesiologist to readjust the intravenous nitroglycerin infusion, as well as fluid administration.

The circumflex approach developed with deep pericardial sutures allows the displacement of the heart without having to directly manipulate the left ventricular wall. This, combined with Trendelenburg positioning of the patient, contributed to maintaining stable hemodynamics, as reported experimentally. ${ }^{19}$ Hypothermia, a problem that we initially encountered, was successfully managed by raising the room temperature, using an intravenous fluid rewarming device, and occasionally using a commercial warm-air ventilated hood device to cover the head and shoulders of the patient.

Limitations of the study. This study has significant limitations. Most important, no systematic control coronary angiographies were performed, albeit for economic and logistic reasons, thereby limiting the assessment of the beating heart operation itself. The first 12 patients were studied, and initial results were good (100\% patency; 95\% good anastomotic result), encouraging us to pursue this approach, which was, at the time, novel..$^{20,21}$ The fact that the CPB cohort had to be chosen from a noncontemporary period might obscure the comparison in hospital stay between the two groups given the recent trends associated with more aggressive discharging. Also, only the short-term clinical followup has been completed, and therefore it is possible that other angina recurrences have not been reported. Finally, only a real randomized study with angiographic control and long-term follow-up will confirm or disprove the value of this procedure.

Areas of caution. We found the treatment of patients with moderately enlarged ascending aorta $(4.0-4.5 \mathrm{~cm})$ that do not necessitate aortic replacement to be a significant area of caution. These patients do not tolerate side-clamping well, which is likely to lead to aortic dissection. Two dissections occurred in this series, and one was repaired immediately during the initial operation. The other patient was discharged and returned 1 week later with an acute dissection at the site of the clamp; the patient died during the surgical attempt to correct the dissection. Both patients had a moderately enlarged ascending aorta.

Reoperative operations were occasionally problematic when a patent venous graft fed a native occluded artery. The side-clamping of the aorta is poorly tolerated in these circumstances, and the surgeon has to rely on internal thoracic arteries when they are available. Another problematic situation relates to ischemic mitral insufficiency. Although CABG can be performed by using the beating heart operative approach in these cases, it does not alleviate the need for a mitral annuloplasty. We now routinely do intraoperative stress transesophageal echocardiography to determine the need for such a procedure.

\section{Conclusion}

Systematic beating heart operative technique through a sternotomy incision is an alternative to conventional CABG on CPB for achieving complete coronary artery revascularization, provided an adequate technique for heart positioning and coronary stabilization. Every surgeon must negotiate a progressive learning curve in attempting increasingly more difficult operations with posterior revascularizations. Long-term clinical and radiologic studies will be necessary to conclusively substantiate these initial results.

\section{REFERENCES}

1. Kolesov VI. Mammary artery-coronary artery anastomosis as a method of treatment of angina pectoris. J Thorac Cardiovasc Surg 1967;54:535-44.

2. Acuff TE, Landreneau RJ, Griffith BP, Mack MJ. Minimally invasive coronary artery grafting. AnnThoracSurg 1996;61:135-7.

3. Kirklin JK. Prospects for understanding and eliminating the deleterious effects of cardiopulmonary bypass. Ann Thorac Surg 1991;51:529-31.

4. Hammerschmidt DE, Stroncek DF, Bowers TK. Complement activation and neutropenia occurring during cardiopulmonary bypass. J Thorac Cardiovasc Surg 1981;81:370-7.

5. Moshkovitz Y, Lusky A, Mohr R. Coronary artery bypass without cardiopulmonary bypass: analysis of short-term and mid-term outcome in 220 patients. J Thorac Cardiovasc Surg 1995;110: 979-87.

6. Buda AJ, Macdonald IL, Anderson MJ, Strauss HD, David TE, Berman ND. Long-term results following coronary bypass operation: importance of preoperative factors and complete revascularization. J Thorac Cardiovasc Surg 1981;82:383-90.

7. Bell MR, Schaff HV, Holmes DR, Fisher LD, Alderman EL, Myers WO, et al. Effects of completeness of revascularization on long-term outcome of patients with three vessel disease undergoing coronary artery bypass surgery: a report from the coronary artery surgery study (CASS) registry. Circulation 1992;86:446-57.

8. Cartier R, Bouchard D, Beaufigeau M, Leclerc Y, Hébert Y. Complete coronary artery revascularization without cardiopulmonary bypass: technical aspects and short-term results. Can J Cardiol 1997;13C:S119C.

9. Cartier R, Blain R. Off-pump revascularization of the circumflex artery: technical aspects and short-term results. Ann Thorac Surg 1999;68:1494-7.

10. Westaby S. Coronary surgery without cardiopulmonary bypass. Br Heart J 1995;73:203-5.

11. Buffolo EA, Andrade JCS, Branco JNR, Aquiar LF, Ribeiro EE, Jatene AD. Myocardial revascularization without extracorporeal circulation: seven years' experience in 593 cases. Eur J Cardiothorac Surg 1990;4:504-8. 
12. Benetti FJ, Naseli G, Wood M, Geffner L. Direct myocardial revascularization without extracorporeal circulation: experience in 700 patients. Chest 1991;100:310-6.

13. Pfister AJ, Zaki MS, Garcia JM, Mispereta LA, Corso PJ. Coronary bypass without cardiopulmonary bypass. Ann Thorac Surg 1992;54:1085-92.

14. Edmunds LH. Inflammatory response to cardiopulmonary bypass. Ann Thorac Surg 1998;66:S12-6.

15. Akins CW, Boucher CA, Pohost GM. Preservation of interventricular septal function in patients having coronary artery bypass grafts without cardiopulmonary bypass. Am Heart J 1984;107:304-9.

16. Benetti FJ, Mariani MA, Ballester C. Direct coronary surgery without cardiopulmonary bypass in acute myocardial infarction. J Cardiovasc Surg (Torino) 1996;37:391-5.

17. Cohn WE, Sirois CA, Johnson RG. Atrial fibrillation after minimally invasive coronary artery bypass grafting: a retrospective, matched study. J Thorac Cardiovasc Surg 1999;117:298-301.

18. Galloway AC, Shemin RJ, Glower DD, Boyer JH, Groh MA, Kuntz RE, et al. First report of the Port Access International Registry. Ann Thorac Surg 1999;67:51-8.

19. Grundeman PF, Borst C, Herwaarden JA, Verlaan CWJ, Jansen EWL. Vertical displacement of the beating heart by the Octopus tissue stabilizer: influence on coronary flow. Ann Thorac Surg 1998;65:1348-52.

20. Cartier R, Hébert Y, Blain R, Tremblay N, Desjardins J, Leclerc $\mathrm{Y}$. Triple coronary artery revascularization on the stabilized beating heart: initial experience. Can J Surg 1998;41:283-8.

21. Cartier R, Beaufigeau M, Hébert Y, Leclerc Y. Off-pump revascularization of the circumflex artery with mechanical stabilization: initial experience. Ann Chir 1997;51:906-11.

\section{Discussion}

Dr Stephen B. Colvin (New York, NY). I greatly enjoyed this thorough review of off-pump CABG experience over 2 years by a single surgeon. The safety and efficacy of offpump CABG are repeatedly being validated. Questions still remain as to the long-term results and even some early adverse myocardial problems. Clearly, there are some other advantages for patients having minithoracotomies versus sternotomies, such as there being no sternal wound problems and minithoracotomy seeming to avoid some of the respiratory problems and allowing for a shorter recovery time and less stay in the hospital. These are being documented both for MIDCAB and for Port-Access CABG.

Over 25 years at New York University (NYU), early on some patients would have an off-pump bypass through a sternotomy, such as those patients who had a failed angioplasty procedure or patients who were operated on through the left side of the chest for obstructions in the circumflex graft that needed an isolated marginal bypass.

Currently, all surgical modalities are being used: sternotomies with $\mathrm{CPB}$, blood cardioplegia or cold fibrillation, off-pump bypasses, Port-Access operations, MIDCAB, and transmyocardial revascularization. About $45 \%$ of the patients now have traditional bypass procedures, $25 \%$ have PortAccess operations, $25 \%$ have off-pump CABG, and about $5 \%$ have MIDCAB. There has been a recent rise in the percentage of off-pump procedures with improved stabilization, such as suction in the Octopus II tissue stabilizer (Medtronic, Inc, Minneapolis, Minn), mechanical devices, "misters," and improved tricks for exposure.

Most of us at NYU believe that minithoracotomies for mitral and aortic valve surgery have significant benefits, and we have somewhat of a bias toward minithoracotomies. We generally use off-pump CABG for our increasing patient population with increased risk, such as the atheromatous aorta or hepatic or renal insufficiency, including patients requiring liver transplantation and those needing revascularization before those procedures.

Our results with Port-Access cardiac bypass have shown excellent results with excellent patency. Hospitalization and transfusion costs are reduced, and recovery is quicker.

This excellent study has tremendous potential but really does not show much in the way of decreased mortality or morbidity rates. Still, there is a significant problem with dissections, wound infections, and the need for inotropic agents, as well as respiratory problems, despite not using the pump.

There is an expanding use of this approach with improved technology, and I think that in a subset of patients, it has tremendous application. However, we must be cautious of the outcomes because early reports have shown late problems with some of the grafts that were done on the beating heart compared with those done with CPB.

Clearly, there is a subset that can be best treated with offpump CABG, but it remains to be seen what the benefits are supposed to be for all patients if complications remain comparable with coronary bypass operations done on-pump, given the better long-term results that we have all seen with CABG done while on-pump.

Dr Cartier. Thank you, Dr Colvin, for your remarks. I agree with you that we will need a long-term study to confirm these findings, but I would say that the task of beating heart surgery is not necessarily to show that it is a better procedure than the standard operation but that it is at least as good. If we can just prove that, it will be something that is very interesting. We can decrease the cost, we can decrease the transfusions, and I believe that for the older patient, outcomes are going to be better.

It is obvious that the Heartport technology (Heartport, Inc, Redwood City, Calif) with the minithoracotomy coupled with the fact that you can do 3 or 4 bypasses through a small thoracotomy could be very interesting to the young population, and I would be very happy to do a study in which these two technologies are compared.

However, as you know, the Heartport technology has not been introduced in Canada yet, and therefore it is not something we have been able to do. In the future, however, I believe we will be able to compare these two techniques and find out which is the worst for younger patients, sternotomy or bypass, and which is the best for the older patients. 